\title{
PENGEMBANGAN MEDIA PEMBELAJARAN MULTIMEDIA \\ INTERAKTIF UNTUK SISWA KELAS 3 SD PADA MATERI \\ SEJARAH UANG MENGGUNAKAN ADOBE FLASH PROFESSIONAL CS6
}

\author{
Efi Trianingrum, Gamaliel Septian Airlanda \\ Surel: 292013014@student.uksw.edu
}

\begin{abstract}
This study aims to develop IPS learning media in the form of interactive multimedia and test the feasibility of interactive multimedia learning media that has been developed. This type of research is research and development $(R \& D)$ which refers to the model developed by Borg and Gall. The results showed the feasibility of interactive multimedia aspects of the media of 4.00, material aspects of 3.23, and language aspects of 4.11. In a limited trial of student questionnaire results showed the feasibility of 4.34 and teacher questionnaires of 4.70. While the questionnaire results of students on a wide test show the feasibility of 4.44. Based on the result of a series of feasibility test process, interactive multimedia developed feasible to be used in IPS learning.
\end{abstract}

Keywords: Development, Interactive Multimedia, IPS

\begin{abstract}
ABSTRAK
Penelitian ini bertujuan untuk mengembangkan media pembelajaran IPS dalam bentuk multimedia interaktif dan menguji kelayakan media pembelajaran multimedia interaktif yang telah dikembangkan. Jenis penelitian ini adalah penelitian dan pengembangan $(R \& D)$ yang mengacu pada model yang dikembangkan oleh Borg and Gall. Hasil penelitian menunjukkan kelayakan multimedia interaktif aspek media sebesar 4.00, aspek materi sebesar 3.23, dan aspek bahasa sebesar 4.11. Pada uji coba terbatas hasil angket siswa menunjukkan kelayakansebesar 4.34 dan angket guru sebesar 4.70. Sedangkan hasil angket siswa pada uji coba luas menunjukkan kelayakan sebesar 4.44. Bedasarkan hasil serangkaian proses uji kelayakan, multimedia interaktif yang dikembangkan layak digunakan dalam pembelajaran IPS.
\end{abstract}

Kata Kunci: Pengembangan, Multimedia Interaktif, IPS

\section{PENDAHULUAN}

Dunia pendidikan sekarang ini

khususnya Sekolah Dasar (SD), menghadapi generasi $\mathrm{Z}$ yang lahir pada rentang tahun 2004-2010. Terdapat 5 generasi yang diperkenalkan kepada dunia sejak munculnya teori generasi (Generation Theory) khususnya setelah perang dunia kedua. Generasi tersebut adalah Baby Boomer (pada tahun 19461964), generasi $X$ (pada tahun 19651980), generasi $Y$ atau generasi milenium (pada tahun 1981-1994),

Program Studi PGSD Universitas Kristen Satya Wacana 
generasi $\mathrm{Z}$ atau $i$ Generation (pada tahun 1995-2010), dan generasi Alpha (pada tahun 2011-2025). Setiap generasi memiliki karakteristik yang berbeda satu satu sama lain. Segala sesuatu yang berhubungan dengan pekerjaan sering dikaitkan dengan karakteristik dari setiap generasi. Hal tersebut dilakukan sebagai upaya mencari jalan tengah agar antar generasi dapat saling mengerti dan memahami.

Generasi $\mathrm{Z}$ disebut juga $i$ Generation, generasi net, atau generasi internet. Anak-anak pada generasi $\mathrm{Z}$ lahir dan dibesarkan di era digital dengan teknologi yang serba ada dan canggih seperti komputer/ laptop, Handphone, internet, dll. 4muda dalam tulisannya yang berjudul "Mengenal Generasi X, Y, dan $\mathrm{Z}$ sebagai Generasi Dominan Masa Kini"(http://www.4muda.com/ mengenal-generasi- $x$-y-dan-z-sebagai -generasi-dominan-masa-kini/), menyatakan bahwa generasi $\mathrm{Z}$ merupakan generasi digital yang mahir dan gandrung akan teknologi informasi dan berbagai aplikasi komputer. Informasi yang mereka butuhkan untuk kepentingan pendidikan maupun pribadi mereka akses dengan cepat dan mudah.

Hasil analisis untuk siswa kelas 3 di empat sekolah yaitu SDN Mangunsari 04 Salatiga, SDN Mangunsari 07 Salatiga, SDN Sidorejo Kidul 03 Salatiga, dan SDN Sidorejo Lor 02 Salatiga menunjukkan bahwa dari 100 siswa, terdapat 41 siswa yang memiliki komputer atau laptop di rumah. Ratarata $43 \%$ siswa menggunakan komputer lebih dari 1 jam dalam sehari. Berbeda dengan hal tersebut dalam sehari justru 53\% siswa menghabiskan waktu untuk belajar kurang dari 1 jam. Adanya fasilitas dan teknologi yang serba ada dan serba canggih untuk anak-anak bagaikan pisau bermata dua. Artinya memiliki banyak manfaat sekaligus memiliki resiko berbahaya jika tidak dimanfaatkan sebagaimana mestinya.

Undang-Undang No. 20 tahun 2003 pasal 1 ayat 1 menyatakan bahwa "Pendidikan adalah usaha sadar dan terencana untuk mewujudkan suasana belajar dan proses pembelajaran agar peserta didik secara aktif mengembangkan potensi dirinya untuk memiliki kekuatan spiritual keagamaan, pengendalian diri, kepribadian, kecerdasan, akhlak mulia, serta keterampilan yang diperlukan dirinya, masyarakat, bangsa dan negara.".

Sekolah sebagai lembaga pendidikan memiliki peran penting dalam proses peningkatan sumber daya manusia terutama untuk menyiapkan generasi $\mathrm{Z}$ yang berkualitas sesuai dengan perkembangan zaman. Program sekolah dilaksanakan secara teratur dan sistematis, dengan sarana dan prasarana yang memadai. Selain itu peran guru sebagai pembimbing akan menghasilkan pemahaman dan penalaran bagi siswa dalam 
mengambil keputusan. Keberhasilan ini tentunya ditentukan oleh berbagai faktor salah satunya adanya keterkaitan antar komponen pembelajaran seperti tujuan, metode, media, materi dan evaluasi pembelajaran.

Ilmu Pengetahuan Sosial (IPS) dalam Permendiknas No. 22 tahun 2006 tentang Standar Isi menyatakan bahwa IPS merupakan salah satu mata pelajaran yang diberikan mulai dari Sekolah Dasar (SD). Adapun yang dikaji dalam IPS sepertiseperangkat peristiwa, fakta, konsep, dan generalisasi yang berkaitan dengan isu sosial. Mata pelajaran IPS dirancang untuk mengembangkan pengetahuan, pemahaman, dan kemampuan analisis terhadap kondisi sosial masyarakat dalam memasuki kehidupan bermasyarakat yang dinamis. $\mathrm{N}$

amun hasil analisis angket untuk 100 siswa menunjukkan sebanyak 41 siswa masih menganggap mata pelajaran IPS sebagai mata pelajaran yang sulit. Sejalan dengan generasi $\mathrm{Z}$ yang gandrung akan teknologi, ternyata sebanyak 77 siswa belum pernah belajar IPS menggunakan komputer. Sementara hasil analisis angket menunjukkan sebanyak 73 siswa lebih suka belajar menggunakan komputer, dan 54 siswa menganggap media komputer lebih mudah untuk memahami pelajaran.

Guru adalah kunci keberhasilan dalam pembelajaran.
Sebagai seorang guru yangakan mentransfer pengetahuan kepada siswa, seharusnya guru melakukan pembaharuan dalam kegiatan pembelajaran. Hasil analisis untuk guru kelas 3 di empat sekolah yaitu SDN Mangunsari 04 Salatiga, SDN Mangunsari 07 Salatiga, SDN Sidorejo Kidul 03 Salatiga, dan SDN Sidorejo Lor 02 Salatiga menyatakan bahwa media pembelajaran IPS yang dimiliki sekolah belum memadai.

Darmawan

(2012:54)

menyatakan bahwa sebelum berkembangnya teknologi komputer bahan pelajaran yang pokok digunakan dalam dunia pendidikan adalah semua yang bersifat Printed Matterial, seperti buku, modul, makalah, majalah, koran, tabloid, jurnal, hand out liflet, buklet, dan sebagainya yang semuanya menggunakan bahan tercetak. Namun kini teknologi informasi memberikan alternatif berupa bahan belajar yang dapat digunakan dan diakses oleh siswa yang tidak dalam bentuk kertas tetapi berbentuk CD, DVD, Flashdisk, dan lain-lain. Inti dari bahan tersebut berupa program/software yang dapat dimanfaatkan apakah sekedar mengambil data, membaca, download, bahkan sampai berinteraksi antara program dengan siswa dan guru dengan memanfaatkan komputer sebagai perangkat utama.

Beberapa sekolah telah memiliki laboratorium komputer yang berisi rata-rata 10 unit komputer yang 
kurang dimanfaatkan secara maksimal dalam pembelajaran. 3 dari 4 sekolah hanya memanfaatkan laboratorium komputer selama 2 jam pelajaran (2x35 menit) dalam seminggu untuk kegiatan pembelajaran komputer, pemanfaatan laboratorium komputer untuk mata pelajaran lain belum pernah dilakukan.

Hal tersebut dikarenakan belum tersedianya bahan ajar yang dapat dimanfaatkan dengan komputer. Bahan ajar yang ada hanya gambar atau video pembelajaran yang cukup ditampilkan dengan media proyektor dimana siswa hanya dapat melihat dan mendengar materi yang disajikan tanpa adanya interaksi. Adanya mata pelajaran komputer setidaknya membuat siswa mampu menjalankan program komputer atau media ajar yang berbasis komputer. Maka dari itu media yang mampu memaksimalkan kemampuan siswa dan memancing siswa agar lebih aktif dalam pembelajaran sangat diperlukan.

Alternatif media yang dapat digunakan dalam pembelajaran adalah media pembelajaran multimedia interaktif. Hasil analisis observasi awal untuk guru menunjukkan 4 dari 4 guru membutuhkan media pembelajaran multimedia interaktif untuk pembelajaran, hal tersebut dikarenakan multimedia interaktif dirasa memiliki manfaat lebih dari $60 \%$. Sejalan dengan hal tersebut 77 dari 100 siswa merasa membutuhkan aplikasi pembelajaran untuk komputer. Media pembelajaran multimedia interaktif dapat membantu siswa melakukan pembelajaran secara mandiri, selain itu pilihan menu yang didesain sedemikian rupa memberi kebebasan kepada siswa untuk memilih materi yang akan dipelajari khususnya dalam pembelajaran IPS dengan topik sejarah uang.

Materi sejarah uang akan lebih menarik bagi siswa jika disampaikan dalam bentuk gambar maupun animasi tentang hal-hal yang bersangkutan dengan kehidupan sehari-hari dibandingkan hanya disampaikan melalui kegiatan ceramah atau melalui buku teks. Multimedia interaktif ini dapat menjadi media pembelajaran yang melibatkan sisi kognitif, afektif dan juga psikomotor anak.

Pengembangan media pembelajaran multimedia interaktif merupakan refleksi dari penelitian yang sudah ada sebelumnya. Terdapat beberapa penelitian yang relevan yaitu: Pertama, penelitian yang dilakukan oleh Arif Mahya Fanny dan Siti Partini (2013) yang mengembangkan multimedia interaktif IPS untuk kelas 5 SD. Kedua, penelitian yang dilakukan oleh Ni Wayan Desi Darmayanti, I Dewa Kade Tastra dan I Kadek Suartama (2014) yang mengembangkan multimedia interaktif IPS untuk kelas 4 SD. Ketiga, penelitian yang dilakukan oleh Nugraheni Dinasari Haryono (2015) yang mengembangkan 
multimedia interaktif untuk kelas 4 SD.

Beberapa penelitian diatas adalah sebagai salah satu upaya dalam rangka mengarahkan siswa untuk memanfaatkan teknologi sebagaimana mestinya khususnya memberikan alternatif cara belajar yang mudah dan menyenangkan sehingga siswa termotivasi dan meningkatkan hasil belajar IPS.

Sesuai dengan permasalahan tersebut diatas maka, penelitian ini bertujuan : (1) Untuk mengetahui cara mengembangkan media pembelajaran multimedia interaktif untuk siswa kelas 3 SD pada mata pelajaran IPS menggunakan Adobe Flash Professional CS6; (2) Untuk menguji kelayakan media pembelajaran multimedia interaktif untuk siswa kelas 3 SD pada mata pelajaran IPS menggunakan Adobe Flash Professional CS6 yang telah dibuat melalui validasi ahli media, ahli materi, ahli bahasa, dan uji coba pada siswa kelas 3 SD.

\section{METODE PENELITIAN}

Jenis penelitian ini adalah penelitian dan pengembangan atau dalam Bahasa inggris Research and Development (R\&D). Borg and Gall (dalam Arifin, 2014:127) mengemukakan "research and development is a powerful strategy for improving practice. It is a process used to develop and validate educational products". Produk pendidikan yang dimaksud dalam penelitian dan pengembangan dalam pernyataan mengandung tiga pengertian pokok, antara lain: produk tidak hanya meliputi perangkat keras tapi juga perangkat lunak; produk dapat berarti produk baru atau memodifikasi produk yang sudah ada; dan produk yang dikembangkan betul-betul bermanfaat bagi dunia pendidikan.

Produk yang dikembangkan dalam penelitian ini adalah media pembelajaran multimedia interaktif pada mata pelajaran IPS dengan materi sejarah uang. Materi sejarah uang adalah materi IPS yang disajikan pada semester II. Materi tersebut dikembangkan sebagai produk multimedia interaktif dengan memanfaatkan program Adobe Flash Professional CS6.Hasil dari pengembangan produk dapat dimasukkan dalam CD (Compact Disc) dan dapat pula disimpan dalam flashdisk.

Prosedur pengembangan yang digunakan dalam penelitian ini menggunakan strategi penelitian dan pengembangan menurut Borg dan Galldalam Arifin (2012:129-132). Terdapat 10 langkah penelitian dan pengembangan menurut Borg dan Gall. Pembuatan media pembelajaran multimedia interaktif ini hanya menggunakan 9 dari sepuluh langkah yang ada, tahapan penelitian dan pengembangan yang dilakukan tidak sampai tahap Dissemination and Implementation. Adapun langkahlangkah yang akan dilakukan yaitu: 1) 
Research and Information Collecting;

2) Planning; 3) Develop Preliminary Form of Product; 4) Preliminary Field Testing; 5) Main Product Revision; 6) Main Field Testing; 7) Operasional Product Revision; 8) Operasional Field Testing; dan 9) Final Product Revision.

Uji coba dilakukan bertujuan untuk menyempurnakan produk media pembelajaran multimedia interaktif dengan mempraktikkannya secara langsung di lapangan. Adapun subjek uji coba dalam penelitian ini adalah sebagai berikut: 1) Uji pakar atau ahli (Expert Judgment) yang terdiri dari pakar yang ahli dalam bidang teknologi komputer, bidang ilmu pengetahuan sosial, dan ahli dalam bidang bahasa; 2) Uji coba terbatas (Preliminary Field Testing) dengan melibatkan 14orang siswa kelas $4 \mathrm{SD}$; dan 3) Uji coba luas (Main Field Testing) yang melibatkan 27 orang siswa kelas 3 SD dalam 1 kelas.

Jenis data yang diperoleh dalam penelitian dan pengembangan ini terdiri dari 2 jenis data, yaitu data kuantitatif dan data kualitatif. Data kuantitatif digunakan untuk melihat kelayakan dan keefektifitasan produk multimedia interaktif yang dikembangkan. Data kuantitatif didapatkan dari hasil lembar validasi pakar atau ahli media, pakar atau ahli materi, pakar atau ahli bahasa, dan angket questionnaire yang diberikan kepada siswa kelas 4 SD, guru kelas 3
SD, dan siswa kelas 3 SD. Sedangkan data kualitatif digunakan untuk mengevaluasi draft produk maupun produk multimedia interaktif yang telah dibuat. Data kualitatif didapatkan dari masukan yang diberikan pakar atau ahli media, pakar atau ahli materi, pakar atau ahli bahasa, dan guru.

Teknik pengumpulan data yang dipakai dalam penelitian ini adalah uji pakar yang dilakukan sebelum uji coba awal dan lapangan, dan non tes yang dilakukan pada saat uji coba awal dan uji coba lapangan. Uji pakar dalam penelitian ini menggunakan uji pakar media, uji pakar materi, dan uji pakar bahasa. Teknik uji pakar digunakan untuk menilai kevalidan dari multimedia interaktif. Teknik nontes yang digunakan adalah angket. Angket diberikan kepada 14 orang siswa kelas 4 SD, 27 orang siswa kelas 3 SD dan guru kelas 3 SD. Angket digunakan untuk menilai keefektifan penggunaan produk multimedia interaktif dengan bentuk angket respons siswa dan angket respons guru.

Skor yang didapatkan dari penilaian pakar atau ahli media, pakar atau ahli materi, pakar atau ahli bahasa, angket respons guru serta angket respons siswa dianalisis menggunakan teknik analisis secara deskriptif. Perhitungan data kuantitatif menggunakan acuan tabel konversi nilai. 
Tabel 1

Pedoman Konversi Skor Kuantitatif Skala 5 ke Data Kualitatif

\begin{tabular}{|c|c|c|}
\hline Jumlah Skor Pernyataan & Rerata Skor & $\begin{array}{c}\text { Klasifikasi } \\
\text { Kinerja }\end{array}$ \\
\hline$($ Mean $+1,5 S D)<x$ & $x>4,01$ & Sangat Baik \\
\hline$($ Mean $+0,5 S D)<x \leq($ Mean $+1,5 S D)$ & $3,34<x \leq 4,01$ & Baik \\
\hline$($ Mean $-0,5 S D)<x \leq($ Mean $+0,5 S D)$ & $2,66<x \leq 3,34$ & Cukup \\
\hline$($ Mean $-1,5 S D)<x \leq($ Mean $-0,5 S D)$ & $1,99<x \leq 2,66$ & Kurang \\
\hline$x \leq($ Mean $-1,5 S D)$ & $x<1,99$ & Sangat kurang \\
\hline
\end{tabular}

Sumber : Supratiknya (2009:158)

Keterangan:

Mean $($ rerata ideal $)=\frac{1}{2}($ skor maksimal ideal + skor minimal ideal $)$

$S D($ standar deviasi ideal $)=\frac{1}{6}$ (skor maksimal ideal - skor minimal ideal $)$

$x=$ skor rerata data empiris

\section{HASIL DAN PEMBAHASAN}

Hasil Validasi Ahli Media

Fokus penilaian pakar media adalah untuk menilai draft produk awal dari sisi kesesuaian media multimedia interaktif yang telah dibuat. Pakar media yang memvalidasi produk multimedia interaktif ini adalah Jasson Prestiliano, ST., M.Cs. (Dosen Program Studi Desain Komunikasi Visual FTI UKSW). Validasi dilakukan pada tanggal 7 Juni 2017 dengan menilai 3 aspek yaitu aspek kemudahan navigasi, menarik minat pembelajaran, dan Fungsi secara keseluruhan. Data kuantitatif yang berupa skor digunakan untuk menentukan kelayakan media, sedangkan data kualitatif yang berupa masukan atau saran digunakan untuk memperbaiki draft produk multimedia interaktif yang dikembangkan. Hasil validasi ahli media disajikan dalam tabel 2 berikut.

Tabel 2

\section{Hasil Validasi Ahli Media}

\begin{tabular}{|l|c|}
\hline \multicolumn{1}{|c|}{ Aspek Penilaian } & $\begin{array}{c}\text { Rata-rata } \\
\text { skor }\end{array}$ \\
\hline Kemudahan Navigasi & 4.67 \\
\hline Menarik minat pembelajaran & 3,88 \\
\hline Fungsi secara keseluruhan & 3.67 \\
\hline Rata-rata skor total & $\mathbf{4 . 0 0}$ \\
\hline
\end{tabular}

Berdasarkan hasil validasi media diatas diperoleh nilai rata-rata kelayakan ahli media sebesar 4.00 dan termasuk dalam kategori baik. Berdasarkan hal tersebut maka kelayakan media dari segi media layak diujicobakan di lapangan.

\section{Hasil Validasi Ahli Materi}

Fokus penilaian pakar materi adalah untuk menilai draft produk awal dari sisi kesesuaian materi 
multimedia interaktif yang telah dibuat. Pakar materi yang memvalidasi produk multimedia interaktif ini adalah Firosalia Kristin, S.Pd., M.Pd. (Dosen Program Studi Pendidikan Guru Sekolah Dasar FKIP UKSW). Validasi dilakukan pada tanggal 8 Juni 2017 dengan menilai 4 aspek yaitu kandungan kognisi, pengetahuan dan presentasi informasi, integrasi media, dan fungsi secara keseluruhan. Data kuantitatif yang berupa skor digunakan untuk menentukan kelayakan media, sedangkan data kualitatif yang berupa masukan atau saran digunakan untuk memperbaiki produk multimedia interaktif yang dikembangkan. Hasil validasi ahli materi disajikan dalam Tabel 3 berikut.

Tabel 3

Hasil Validasi Ahli Materi

\begin{tabular}{|l|c|}
\hline \multicolumn{1}{|c|}{ Aspek Penilaian } & $\begin{array}{c}\text { Rata-rata } \\
\text { skor }\end{array}$ \\
\hline Kandungan kognisi & 3,33 \\
\hline $\begin{array}{l}\text { Pengetahuan dan presentasi } \\
\text { informasi }\end{array}$ & 3.40 \\
\hline Integrasi media & 3.00 \\
\hline Fungsi secara keseluruhan & 3.00 \\
\hline Rata-rata skor total & $\mathbf{3 . 2 3}$ \\
\hline
\end{tabular}

Berdasarkan hasil validasi materi diatas diperoleh nilai rata-rata kelayakan ahli materi sebesar 3.23 dan termasuk dalam kategori cukup. Bedasarkan hal tersebut maka kelayakan media dari segi materi layak diujicobakan di lapangan.
Hasil Validasi Ahli Bahasa

Fokus penilaian pakar bahasa adalah untuk menilai kelayakan draft produk awal dari segibahasa tulis dan bahasa lisan yang disampaikan melalui video yang digunakan dalam multimedia interaktif yang telah dibuat. Pakar bahasa yang memvalidasi produk multimedia interaktif ini adalah Dr. Henny Dewi K., M.Pd. (Dosen Program Studi Pendidikan Guru Sekolah Dasar FKIP UKSW). Validasi dilakukan pada tanggal 13 Juni 2017 dengan menilai 3 aspek yaitu aspek kebakuan bahasa, kemudahan memahami makna, dan keefektifan kalimat. Data kuantitatif yang berupa skor digunakan untuk menentukan kelayakan media, sedangkan data kualitatif yang berupa masukan atau saran digunakan untuk memperbaiki produk multimedia interaktif yang dikembangkan. Hasil validasi ahli bahasa disajikan dalam Tabel 4 berikut.

Tabel 4

Hasil Validasi Ahli Bahasa

\begin{tabular}{|c|c|}
\hline Aspek Penilaian & $\begin{array}{l}\text { Rata-rata } \\
\text { skor }\end{array}$ \\
\hline Kebakuan Bahasa & 4.33 \\
\hline $\begin{array}{l}\text { Kemudahan memahami } \\
\text { makna }\end{array}$ & 4.00 \\
\hline Keefektifan kalimat & 4.00 \\
\hline Rata-rata skor total & 4.11 \\
\hline
\end{tabular}

Berdasarkan hasil validasi materi diatas diperoleh nilai rata-rata kelayakan ahli bahasa sebesar 4.11 dan termasuk dalam kategori sangat layak. Bedasarkan hal tersebut maka 
kelayakan media dari segi bahasa layak diujicobakan di lapangan.

\section{Hasil Uji Coba Lapangan}

Uji coba lapangan dilakukan 2 kali yaitu uji coba terbatas dengan melibatkan 14 siswa kelas 4 SD dan guru kelas 3. Sedangkan pada uji coba luas melibatkan 27 siswa kelas 3 SD.

a. Hasil Angket Uji Coba Terbatas

Uji coba terbatas melibatkan 14 orang siswa kelas 4 SD Negeri Salatiga 12. Uji coba ini dilakukan pada tanggal 20 Juli 2017. Penilaian dilakukan dengan angket uji kelayakan pengguna yang terdiri atas tiga aspek yaitu aspek isi materi, interaksi pengguna, dan ketertarikan siswa. Data hasil uji coba tersebut disajikan dalam Tabel 5 berikut.

Tabel 5

Hasil Uji Coba Terbatas

\begin{tabular}{|l|c|}
\hline \multicolumn{1}{|c|}{ Aspek Penilaian } & $\begin{array}{c}\text { Rata-rata } \\
\text { skor }\end{array}$ \\
\hline Isi Materi & 4.31 \\
\hline Interaksi Pengguna & 4.30 \\
\hline Ketertarikan Siswa & 4.39 \\
\hline Rata-rata skor total & $\mathbf{4 . 3 4}$ \\
\hline
\end{tabular}

Berdasarkan tabel 5, dapat dilihat bahwa rata-rata hasil uji coba terbatas sebesar 4.34 dan masuk dalam kategori sangat baik. Seluruh aspek mendapatkan rata-rata skor dalam kategori sangat baik, maka media layak digunakan dalam pembelajaran.

b. Hasil Angket Uji Coba Luas

Uji coba terbatas melibatkan 27 orang siswa kelas 3 SD
Negeri Salatiga 12. Uji coba ini dilakukan pada tanggal 21 Juli 2017. Penilaian dilakukan dengan angket uji kelayakan pengguna yang terdiri dari 3 aspek yaitu aspek isi materi, interaksi pengguna, dan ketertarikan siswa. Data hasil uji coba tersebut disajikan dalam Tabel 6 berikut ini.

Tabel 6 Hasil Uji Coba Luas

\begin{tabular}{|l|c|}
\hline \multicolumn{1}{|c|}{ Aspek Penilaian } & $\begin{array}{c}\text { Rata-rata } \\
\text { skor }\end{array}$ \\
\hline Isi Materi & 4.57 \\
\hline Interaksi Pengguna & 4.19 \\
\hline Ketertarikan Siswa & 4.57 \\
\hline \multicolumn{1}{|c|}{ Rata-rata skor total } & $\mathbf{4 . 4 4}$ \\
\hline
\end{tabular}

Berdasarkan tabel 6, dapat dilihat bahwa rata-rata hasil uji coba terbatas sebesar 4.44 dan masuk dalam kategori sangat baik. Seluruh aspek mendapatkan rata-rata skor dalam kategori sangat baik, maka media layak digunakan dalam pembelajaran.

c. Hasil Angket Guru Kelas

Pengisian angket oleh guru kelas 3 SD dilakukan pada uji coba terbatas di SDN Salatiga 12 yaitu pada tanggal 20 Juli 2017. Terdapat 10 butir pertanyaan dalam menilai produk multimedia interaktif. Secara umum, hasil dari angket guru pada uji coba terbatas menunjukkan bahwa multimedia interaktif yang dikembangkan mendapatkan skor rata-rata 4.7 dan termasuk dalam kategori sangat baik. 
Kajian Produk Akhir

Produk akhir dari hasil penelitian dan pengembangan ini adalah media pembelajaran Multimedia Interaktif "Belajar Mengenal Sejarah Uang" untuk siswa kelas 3 SD. Multimedia interaktif tersebut berisi:

a. Halaman Awal: merupakan halaman pertama yang muncul saat program dijalankan. Berisi musik dan tulisan "Belajar Mengenal Sejarah Uang" yang dilengkapi dengan tombol "masuk" untuk menjalankan program tersebut.

b. Halaman proses: pada halaman proses terdapat tulisan "loading" dan dilengkapi dengan animasi uang yang secara bergiliran masuk ke dalam celengan ayam dan setelah selesai celengan tersebut pecah.

c. Halaman Menu: pada halaman menu terdapat musik dan tulisan "Belajar Mengenal Sejarah Uang" dan dilengkapi beberapa pilihan tombol meliputi SK KD, materi, permainan, kesimpulan, petunjuk penggunaan, tentang program, dan keluar.

d. Halaman Petunjuk: pada halaman petunjuk terdapat penjelasan dari setiap tombol yang ada pada multimedia yang dikembangkan.

e. Halaman Tentang Program: pada halaman tentang program terdapat profil dari pengembang produk multimedia interaktif dan disertakan sumber materi ataupun gambar yang ada pada multimedia interaktif.

f. Halaman SK KD: pada halaman SK KD akan ditampilkan SK (Standar Kompetensi), KD (Kompetensi Dasar), dan tujuan pembelajaran.

g. Halaman Materi: pada halaman materi akan ditampilkan pilihan materi yang ada pada multimedia interaktif. Adapun pilihan materi yang disajikan adalah materi "Sejarah Uang" yang berisi tentang video animasi singkat tentang sejarah uang dan materi "jenis-jenis uang" yang berisi tentang penjelasan jenis-jenis uang beserta contoh-contoh uang yang ada di Indonesia.

h. Halaman Permainan: pada halaman permainan siswa diminta menggerakkan lingkaran merah sesuai arah yang diinginkan, setelah siswa melewati uang akan ditampilkan soal pilihan ganda. Jika siswa menjawab jawaban yang sesuai maka akan muncul penghargaan berupa skor uang yang bertambah.

i. Halaman Kesimpulan: pada halaman kesimpulan memuat rangkuman materi dari materi sejarah uang.

\section{SIMPULAN}

Bedasarkan pembahasan dari hasil penelitian pengembangan multimedia interaktif "Sejarah Uang" dapat disimpulkan bahwa. 
Pertama, pembelajaran yang dikembangkan pada penelitian ini adalah materi Sejarah Uang untuk siswa kelas 3 SD. Multimedia interaktif "Belajar Mengenal Sejarah Uang" dikembangkan dengan menggunakan aplikasi Adobe Flash Professional CS6 dengan bantuan beberapa aplikasi lain seperti Adobe Photoshop CS6 untuk membuat dan mengedit gambar yang akan digunakan, Adobe Premiere Pro CS6 untuk mengedit video, dan Adobe After Effect CS6 untuk membuat animasi. Hasil dari draft awal multimedia interaktif diujikan melalui validasi pakar media, pakar materi, dan pakar bahasa. Setelah dilakukan penilaian oleh para pakar, draft produk direvisi sesuai masukan para pakar. Setelah draft produk direvisi sesuai dengan masukan dilanjutkan dengan uji coba lapangan dengan dilakukannya uji coba terbatas yang melibatkan siswa kelas 4 SD serta guru kelas $3 \mathrm{SD}$, dan uji coba luas yang melibatkan siswa kelas $3 \mathrm{SD}$.

Kedua, multimedia interaktif yang dikembangkan ini sudah layak digunakan sebagai media pembelajaran IPS. Hal tersebut ditunjukkan bedasarkan hasil validasi pakar dan uji coba lapangan. Nilai rata-rata yang diperoleh dari validasi pakar media adalah 4.00 (baik), nilai rata-rata yang diperoleh dari validasi pakar materi adalah 3.23 (cukup), dan nilai rata-rata yang diperoleh dari validasi pakar bahasa adalah 4.11 (sangat baik). Nilai rata-rata yang diperoleh dari hasil uji coba terbatas dari angket siswa adalah 4.34 (sangat baik) dan angket guru adalah 4.70 (sangat baik). Sedangkan Nilai ratarata hasil angket siswa pada uji coba luas adalah 4.44 (sangat baik).

\section{DAFTAR RUJUKAN}

4muda. 2015.Mengenal Generasi X, $Y$, dan $Z$ sebagai Generasi Dominan Masa Kini. (online),(http://www.4muda.c $\mathrm{om} /$ mengenal-generasi-x-ydan-Z-sebagai-generasidominan-masa-kini/, diakses 16 Januari 2017).

Arifin, Zainal. 2014. Penelitian Pendidikan: Metode dan Paradigma Baru. Bandung: Remaja Rosdakarya.

Darmayanti, N.W.D., I Dewa K.T., dan I Kadek Suartama. 2014. Pengembangan Multimedia Pembelajaran Interaktif pada mata pelajaran IPS di SD No 3 Darmasaba. E-Jurnal Edutech Universitas Pendidikan Ganesa Volume 2 No 1 Halaman 1-11.

Darmawan, Deni. 2012. Inovasi Pendidikan: Pendekatan Praktik Teknologi Multimedia dan Pembelajaran Online. Bandung: Remaja Rosdakarya.

Fanny, Arif Mahya. 2013. Pengembangan Multimedia 
Interaktif untuk Mata

Pelajaran Ilmu Pengetahuan

Sosial (IPS) Sekolah Dasar

Kelas $V$. Jurnal Prima

Edukasia Volume I, Nomor 1

Halaman 1-9.

Haryono, Nugraheni Dinasari. 2015.

Pengembangan Multimedia
Interaktif sebagai Media

Pembelajaran IPS Bagi Siswa

Kelas IV SD Negeri

Tegalpanggung. Jurnal

Pendidikan Guru Sekolah

Dasar Edisi 17 Tahun ke IV September 2015. Halaman 19. 